\title{
QUALITY CONTROL IN MEDICAL EDUCATION
}

Among recent years there has been a raging controversy about the control of quality of the medical graduated we produce here. The quality control has been defined as a process for ensuring proper standard in the production. It means that the products should confirm to the set of quality fixed by a tangible standards.

The assessment of the quality of the product in manufacturing sector is easy but in the field of education relating to humanities and medical science the task is formidable. For this, in education regulatory authorities have been created in form of Universities who develop the curricula, syllabi \& conduct elaborate examinations at multiple levels. The students are not only declared pass or fail but are also graded.

In medical science, there is an added regulating authority in the form of Medical Councils which have vast statutory powers not only over quality of medical schools but also the teachers. If there is a doubt about the quality of the doctors produces, the best way is to strengthen these regulatory authorities rather than creating an extra constitutional watchdog. After all too many cooks are known to spoil the broth. But before we censor an existing system for inadequate quality control, we must have an incontrovertible evidence that quality is really poor. An arbitrary poor-quality branding by know all would prove to be a tendentious remark and would unjustifiably debase the system.

There is another way to judge the quality of our medical students. If our students are successfully competing the examinations held in other countries in the form of screening tests or licensing exams, there is hardly any reason to worry. The doctors from here are known to have secure very high percentile in USMLE and at other places. It is certainly not due to a sweet serendipity.

It must also be considered that medical institutions are not only producing doctors but represent an important contributors to the economic health of the country. Nowadays medical entrepreneurship is not looked down on condescendingly.

If there are no firm reasons to believe that quality of medical graduates are poor in this country, there is hardly any reason for railroading the medical schools for reducing seats.

Prof. S. M. Mishra

M.S. (Surgery), M.S. (Ortho.), F.R.C.S.

Editor-in-Chief 